\title{
GAME EXPLORE SUMATERA ISLAND SEBAGAI MEDIA PELESTARIAN BUDAYA BANGSA
}

\author{
Aditio Reza Ramadhan \\ Program Studi Informatika \\ Fakultas Teknik dan ilmu Komputer Universitas Teknokrat Indonesia \\ Jl. H.ZA Pagaralam, No 9-11, Labuhanratu,Bandarlampung \\ Email : aditiorezatekno12@gmail.com
}

\begin{abstract}
The island of Sumatra is the 3rd largest island in Indonesia which has an area of 473,481 km2. The island of Sumatra has a variety of cultures, one of which is the unique traditional clothing in each region. This research will discuss about designing and building adventure games about culture. The game contains culture on the island of Sumatra, the game is named the Sumatra Island Explore Game. The culture that will be included in the Sumatra Island Explore Game is traditional clothing on the island of Sumatra. The purpose of making this game is to introduce and preserve the culture in the form of traditional clothing on the island of Sumatra. The development of this game uses Construct 2 tools and several other supporting tools such as Corel Draw X5, Photoshop CS6. The results of the game implementation have been tested by alpha and beta testing. Alpha testing is through testing the functionality aspects with the blackbox method, and can run well with $100 \%$ validation. Beta testing goes through the usability aspect, and the results are $80 \%$, while the system software testing is quite good on some devices. From the results of these tests, it can be concluded that the Sumatra Island Game Explore application can run well and can be used.
\end{abstract}

Keyword: game, traditional clothes, Construct 2, culture, android.

\begin{abstract}
Abstrak
Pulau sumatera merupakan pulau ke-3 terbesar di indonesia pulau yang memiliki luas $473,481 \mathrm{~km}^{2}$. Pulau sumatera memiliki kebudayaan yang beragam salah satunya keunikan pakaian adat di tiap daerahnya. Penelitian ini akan membahas tentang merancang dan membangun game petualangan tentang budaya. Game tersebut berisi kebudayaan yang ada di pulau sumatera, game tersebut diberi nama Game Explore Sumatera Island. Kebudayaan yang akan dimasukkan ke dalam Game Explore Sumatera Island ini adalah pakaian adat di pulau sumatera. Tujuan dari pembuatan game ini adalah untuk memperkenalkan dan melestarikan budaya berupa pakaian adat yang ada dipulau sumatera. Pembangunan game ini menggunakan tools Construct 2 dan beberapa tools pendukung lainnya seperti, corel draw x5, photoshop cs6. Hasil implementasi game telah diuji dengan pengujian alpha dan beta. Pengujian alpha melalui pengujian aspek fungsionalitas dengan metode blackbox, dan dapat berjalan dengan baik dengan validasi 100\%. Pengujian beta dengan melalui aspek usability, dan didapatkan hasil $80 \%$, sedangkan untuk pengujian perangkat lunak sistem cukup baik di beberapa perangkat. Dari hasil pengujian tersebut, dapat disimpulkan bahwa aplikasi Game Explore sumatra Island dapat berjalan dengan baik dan dapat digunakan.
\end{abstract}

Kata Kunci: Game, Pakaian Adat, Construct 2, Kebudayaan, android.

\section{Pendahuluan}

\section{A. Latar Belakang}

Game merupakan suatu hiburan yang dapat menjadi pilihan ketika waktu senggang, di zaman modern ini sudah banyak jenis hiburan berupa game dalam bentuk perangkat lunak yang dapat dimainkan di berbagai platform salah satunya platform android. Pada saat ini game android lebih digemari karena hanya dengan smartphone berbasis android pengguna dapat bermain game kapan saja dan dimana saja. Game sendiri memiliki berbagai macam genre seperti adventure, puzzle, action, rpg, dan lain-lain.

Dalam adventure game, pengguna dituntut kemampuan berfikir untuk menganalisa tempat secara visual, memecahkan teka-teki maupun menyimpulkan rangkaian peristiwa dan percakapan karakter menggunakan benda-benda yang tepat dan diletakan ditempat yang tepat. Gameplay jenis ini adalah keharusan pengguna memecahkan bermacam-macam puzzle melalui interaksi dengan orang lingkungan dalam game tersebut. Game jenis adventure telah banyak dikembangkan ke dalam bentuk console game, pc game maupun platform android salah satu tools yang mendukung untuk membuat game berbasis android adalah scirra construct 2

Construct 2 adalah salah satu tools pembuatan game 2 dimensi berbasis android yang simpel dan mudah dipahami karna hanya menggunakan drag and drop saja tanpa adanya coding. Jadi untuk game yang akan dibangun oleh peneliti yang berbasis android sangat cocok 
menggunakan construct 2 .

Sumatera adalah pulau keenam terbesar di dunia yang terletak di indonesia, dengan luas $473,481 \mathrm{~km}^{2}$ [6]. Pulau ini dikenal pula dengan nama lain yaitu Percha, Andalas, atau dalam bahasa sansekerta Suwarnadwipa yang berarti pulau emas. dalam Naskah Negarakertagama dari abad ke14 juga menyebutkan "Bumi Melayu" (Melayu) untuk pulau ini. sesuai dengan sejarahnya pulau ini dihuni sebagian besar penduduk adat melayu yang tersebar dari aceh hingga lampung.

Peneliti menambahkan unsur budaya Indonesia terutama Sumatera pada gameplay yg akan dibangun ini, yaitu berupa pakaian adat. Dengan demikian diharapkan agar game ini lebih memiliki nilai pengetahuan tentang budaya Sumatera, khususnya pakaian adat. Hal tersebut diharapkan dapat menarik minat pengguna game. Tujuan lain dari penelitian ini adalah memperkenalkan dan melestarikan budaya Indonesia yaitu pakaian adat.

B. Tinjauan Pustaka

1) Ada beberapa penelitian mengenai game, yang telah diteliti sebelumnya antara lain pada penelitian [1], tentang Game Edukasi Platform Belajar Matematika Berbasis Android Menggunakan Construct 2. Kemudian pada penelitian game lainnya antara lain pada [6] [7] [8] [9] [10].

\section{2). Game}

Dalam kamus bahasa Indonesia "Game" diartikan sebagai permainan. Permainan merupakan bagian dari bermain dan bermain juga bagian dari permainan keduanya saling berhubungan. Permainan adalah kegiatan yang kompleks yang di dalamnya terdapat peraturan, play dan budaya. Sebuah permainan adalah sebuah sistem dimana pemain terlibat dalam konflik buatan, disini pemain berinteraksi dengan sistem dan konflik dalam permainan merupakan rekayasa atau buatan, dalam permainan terdapat peraturan yang bertujuan untuk membatasi perilaku pemain dan menentukan permainan. Game bertujuan untuk menghibur, biasanya game banyak disukai oleh anak-anak hingga orang dewasa. Games sebenarnya penting untuk perkembangan otak, untuk meningkatkan konsentrasi dan melatih untuk memecahkan masalah dengan tepat dan cepat karena dalam game terdapat berbagai konflik atau masalah yang menuntut kita untuk menyelesaikannya dengan cepat dan tepat. Tetapi game juga bisa merugikan karena apabila kita sudah kecanduan game kita akan lupa waktu dan akan mengganggu kegiatan atau aktifitas yang sedang kita lakukan.

\section{3). Konsep Dasar Pembuatan Game}

Dalam hal pembuatan game, tentu saja ada tahap-tahap yang harus dilalui untuk kesempurnaan game tersebut. Pada [4] ada beberapa tahapan dalam pengemabngan game. Berikut tahap-tahap dalam pembuatan sebuah game antara lain.

\section{A. Genre Game}

Ada beberapa genre game antaralain Arcade, Racing, Fighting, Fun Games, FPS (First Person Shooter), RTS (Real Time Strategy), RPG (Role Playing Game), atau Simulation

B. Tools
Tentukan Tool yang ingin digunakan. Ini bagian yang terpenting, dengan apakah game tersebut dibuat. Biasanya game dibuat dengan bantuan perangkat lunak dan bahasa pemrograman.

C. Gameplay

Gameplay adalah sistem jalannya game tersebut, mulai dari menu, area permainan, save, load, game over, story line, mission success, mission failed, cara bermain dan sistem lainnya harus ditentukan. Sebisa mungkin gameplay dibuat agar menarik untuk dimainkan dan tidak menyulitkan pemain sehingga pemain merasa nyaman ketika memainkan game

D. Grafis

Jenis grafis secara sederhana dapat dibagi menjadi tiga jenis yaitu kartun, semi realis, atau realis. Pilih jenis grafis yang sesuai dengan kebutuhan game, kemudian pilih software apa yang ingin digunakan dalam membuat gambarnya.

E. Suara

Tanpa suara akan membuat game kehilangan nilainya. Karena itu, pilihlah suara yang ingin digunakan dalam permainan. Pilihan suara bisa dibagi menjadi beberapa bagian main menu, save menu, load menu, shoot, dead, mission success, mission failed, loading dan bagianbagian lainnya. Pemilihan suara yang digunakan haruslah seirama dengan bagiannya, misal untuk bagian mission failed tidak cocok jika menggunakan musik yang bersemangat, haruslah musik yang mengandung unsur kesedihan untuk didengar sehingga akan membuat pemain makin sedih ketika kalah.

F. Timeline

Lakukan perencanaan waktu. Dengan perencanaan waktu akan membuat perancang game makin bebas melakukan hal lainnya karena perasaan perancang tidak lagi terganggu dengan game yang belum selesai dibuat. Kemudian ketika waktu pembuatan game sudah tiba, perancang akan membuat game sesuai dengan urutan waktu yang sudah ditentukan sehingga tidak bingung bagian game mana yang belum selesai dikerjakan.

\section{G. Pembuatan}

Lakukan pembuatan game karena semua komponen yang diperlukan sudah disiapkan dari awal. Lakukan proses pembuatan berdasarkan waktu yang sudah ditentukan

\section{H. Publishing}

Lakukan publishing. Ketika sudah selesai membuat game, publish game menjadi setup. Jika game harus diinstal terlebih dahulu sebelum dimainkan atau di publish menjadi .exe, jika game dapat langsung dimainkan tanpa harus menginstalnya terlebih dahulu, metode mempublish tergantung dengan tool yang digunakan untuk membuat game.

\section{Pembahasan}

\section{A. Metode Pengembangan Sistem}

Yang dimaksud dengan metodologi adalah tata cara yang menentukan proses apa yang akan digunakan. Dalam multimedia, terdapat banyak metodologi yang dipakai untuk mengembangkan multimedia. Sebuah 
produk bisa diciptakan dengan berbagai metodologi oleh organisasi pengembang. Menurut Luther pada penelitian[9], metodologi pengembangan multimedia terdiri dari enam tahap, yaitu konsep, desain, pengumpulan materi, pembuatan, pengujian dan distribusi.

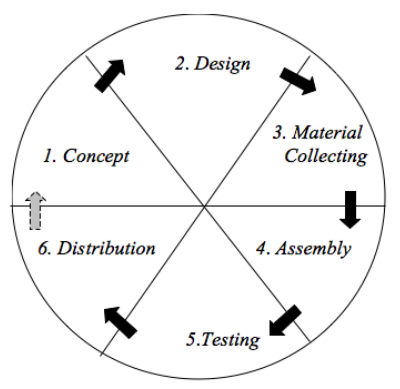

Gambar 1 Tahap Pengembangan Multimedia[9]

\section{a. Pengonsepan (Concept)}

Pada penelitian ini akan dikembangkan sebuah game dengan tujuan mengenalkan kepada pengguna atau gamer budaya dan karakteristik sumatera. Pada gambar 2 adalah konsep karakter dalam game yang dibuat.

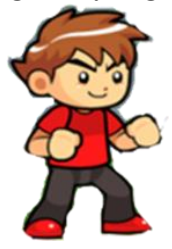

Gambar 2. Konsep Karakter Game

b. Desain (Design)

Pada tahap desain dilakukan menggunakan scirra construct 2 yaitu aplikasi pembuat game 2D dikembangkan oleh scirra Ltd. Pembuat mendesain game explore sumatera island agar dapat berjalan di berbagai perangkat. Dengan menggunakan Construct 2 tidak membutuhkan pengkodean. Pada tahap desain menggunakan dua metode yaitu flowchart dan storyboard berikut tampilan nya.

\section{Flowchart Sistem}

Berikut adalah gambar flowchart, setelah pemain masuk terdapat empat button menu yaitu button main, button tentang, button suara dan button keluar

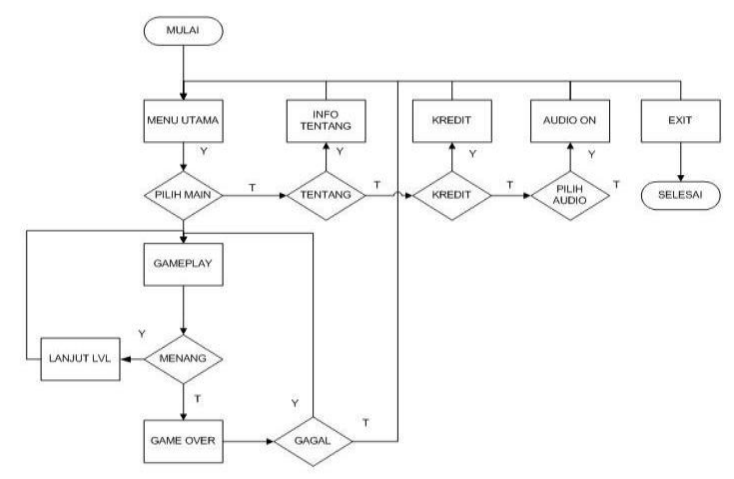

Gambar 3. Flowchart Sistem

\section{Storyboard}

berikut adalah desain storyboard

\begin{tabular}{|c|c|c|}
\hline \multirow[t]{4}{*}{ souno } & $\begin{array}{l}\text { EXPLORE } \\
\text { SUMATERA } \\
\text { ISLAND }\end{array}$ & \\
\hline & mew & \\
\hline & 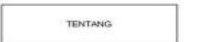 & \\
\hline & & Keluar \\
\hline
\end{tabular}

Gambar 4. Rancangan Menu Utama

Menu utama

Pada menu utama terdapat empat tombol yaitu

- Tombol main untuk memulai permainan

- Tombol tentang berisi informasi tentang kredit

- Tombol suara untuk mematikan dan menghidupkan suara

- Tombol keluar untuk keluar dari permainan

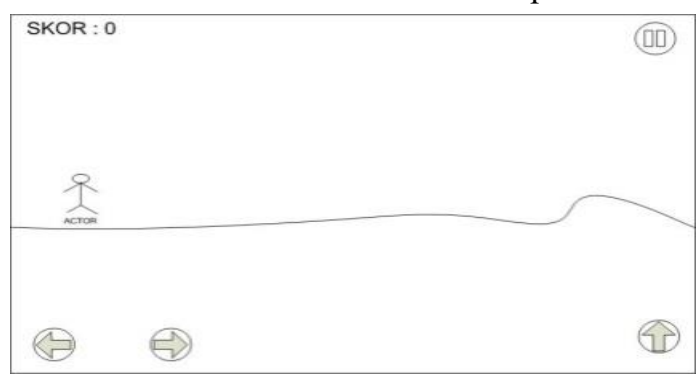

Gambar 5. Rancangan mulai permainan

Menu Mulai permainan

- $\quad$ Pada menu mulai permainan terdapat satu tombol yaitu kembali

- Terdapat peta pulau sumatera

- Terdapan delapan titik mini level permainan yang ditandai dengan nama daerah dipulau sumatera dimulai dari aceh hingga provinsi lampung.

c. pengumpulan bahan (Material Collection)

pengumpulan bahan dilakukan dengan mencari image atau gambar audio, foto digital, background dan image pendukung lainnya.

Tabel 1. Pakaian Adat Sumatera

\begin{tabular}{|c|c|c|c|}
\hline No. & Provinsi & $\begin{array}{c}\text { Nama } \\
\text { Pakaian }\end{array}$ & $\begin{array}{c}\text { Pakaian Adat } \\
\text { Tradisional Indonesia }\end{array}$ \\
\hline 1. & $\begin{array}{l}\text { Banda } \\
\text { Aceh }\end{array}$ & $\begin{array}{l}\text { Ulee } \\
\text { Balang }\end{array}$ & \\
\hline
\end{tabular}




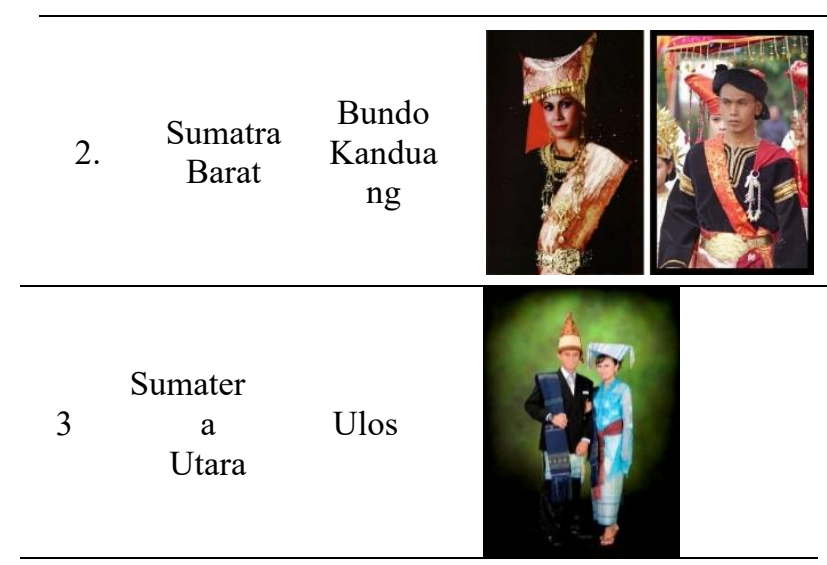

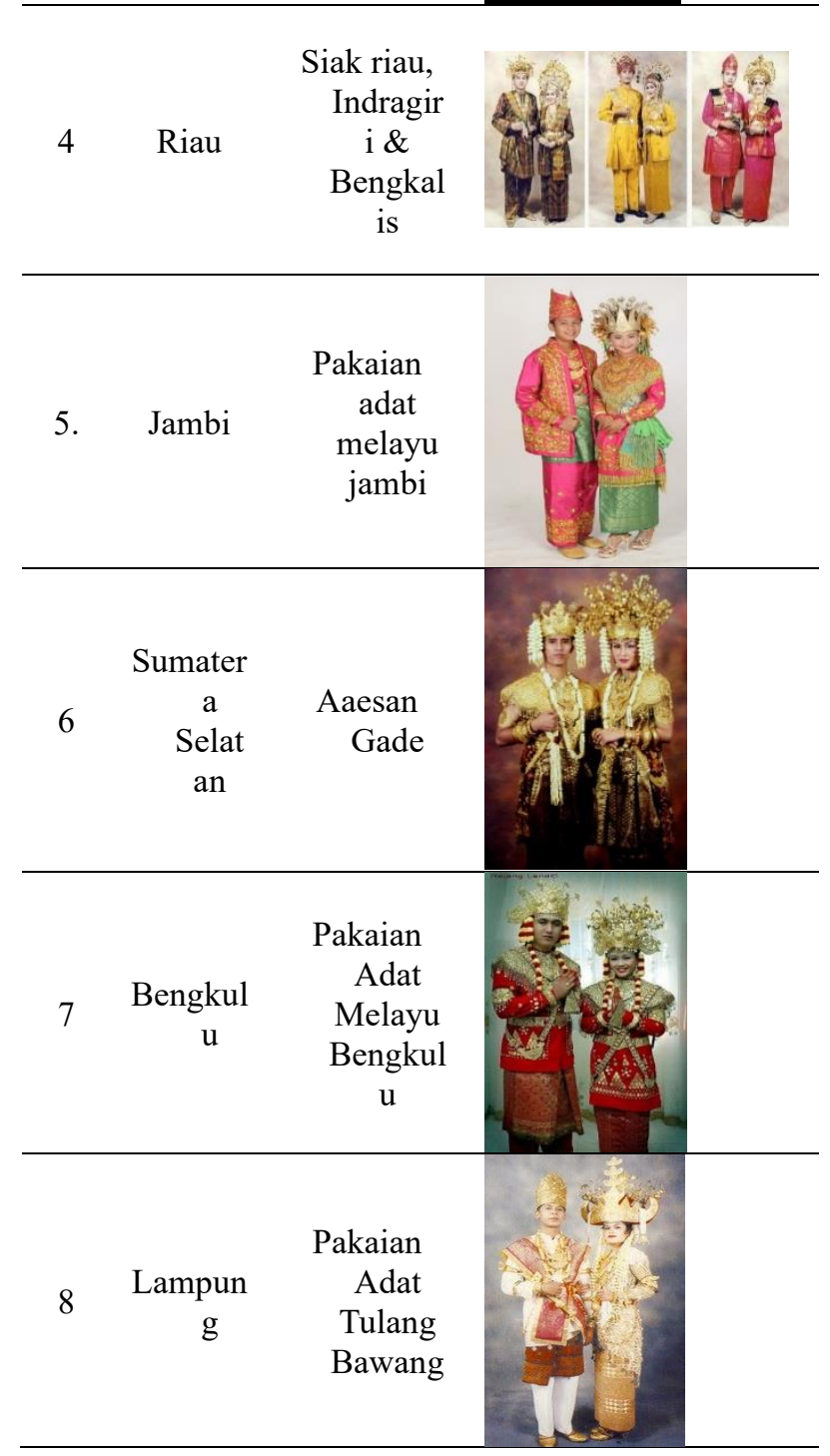

\section{d. Assembly}

Pada tahap ini adalah setelah dari konsep dan rancangan telah dibuat diimplemetasikan ke dalam tools. Tahap assembly adalah tahap pembuatan semua objek atau bahan multimedia. Pembuatan aplikasi didasarkan pada tahap desain, seperti storyboard, bagan alir, dan struktur navigasi. Tahap ini biasanya menggunakan perangkat lunak authoring, seperti Macromedia Director. Macromedia Flash atau produk open source yang gratis, yaitu Sophie yang dapat berjalan di Linux maupun di Mac OS X juga dapat digunakan. Berikut adalah hasil dari assembly.

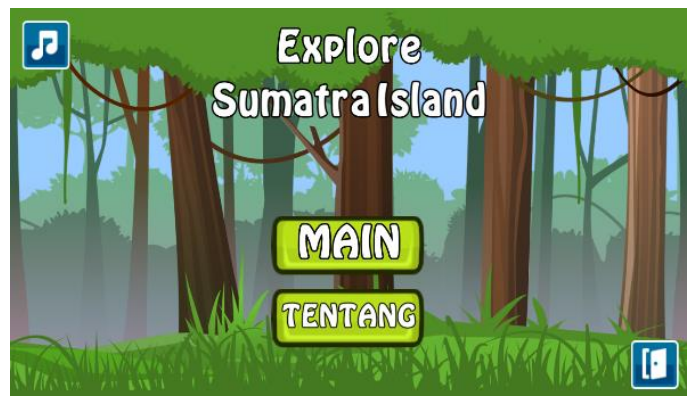

Gambar 6. Tampilan Menu Utama

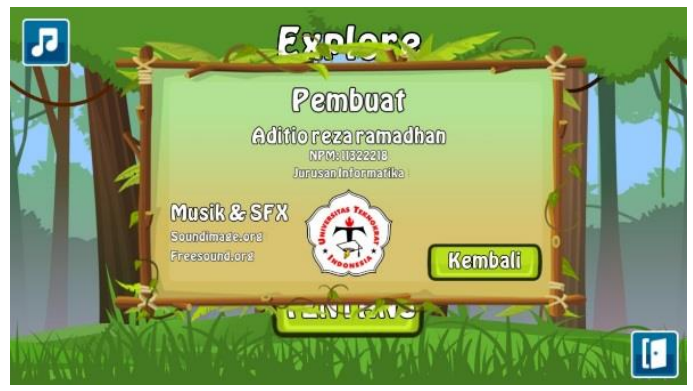

Gambar 7. Tampilan menu tentang

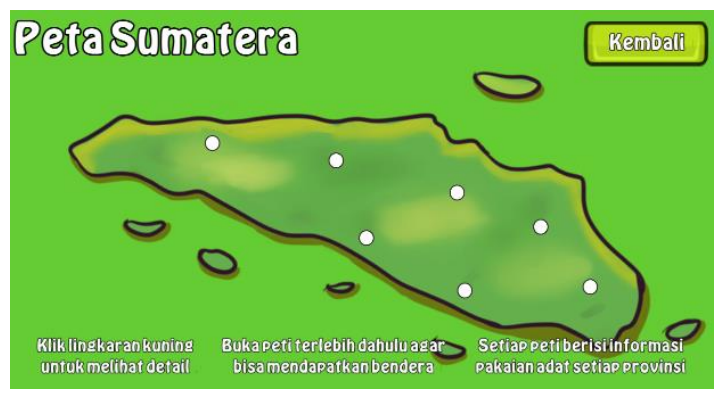

Gambar 8. Tampilan menu peta sumatera

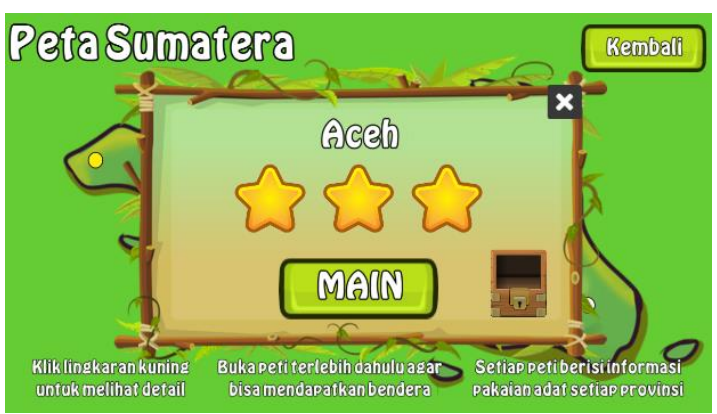

Gambar 9. Tampilan menu main

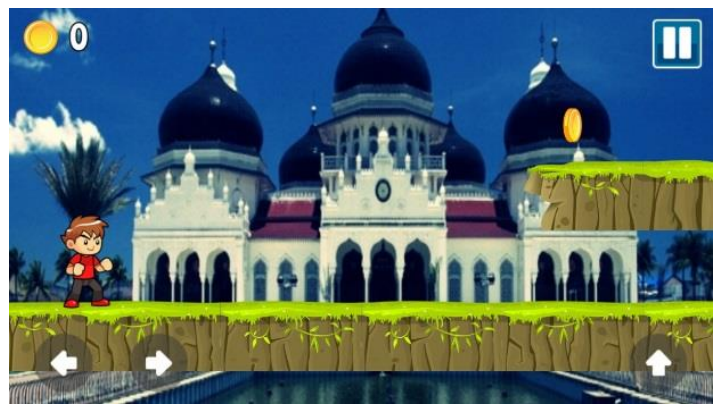

Gambar 10. Tampilan menu gameplay 


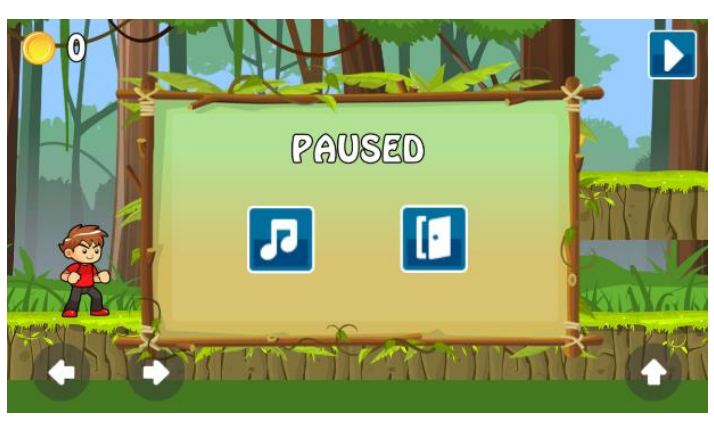

Gambar 11. Tampilan menu pause

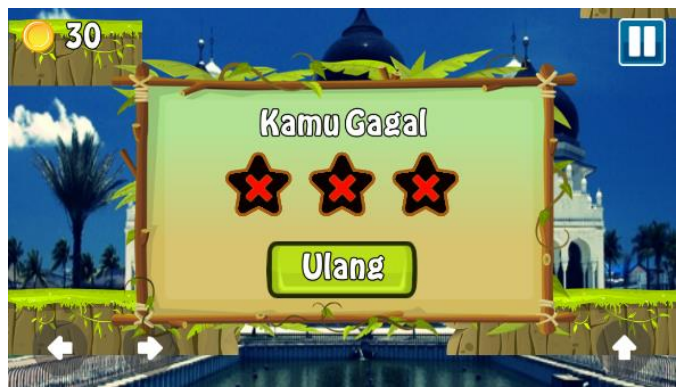

Gambar 12. Tampilan game over

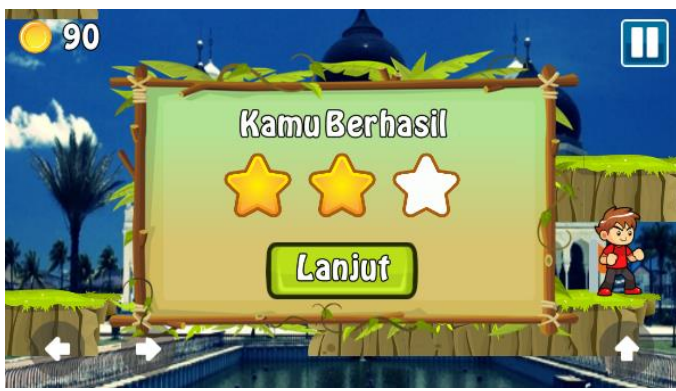

Gambar 13. Tampilan lanjut level

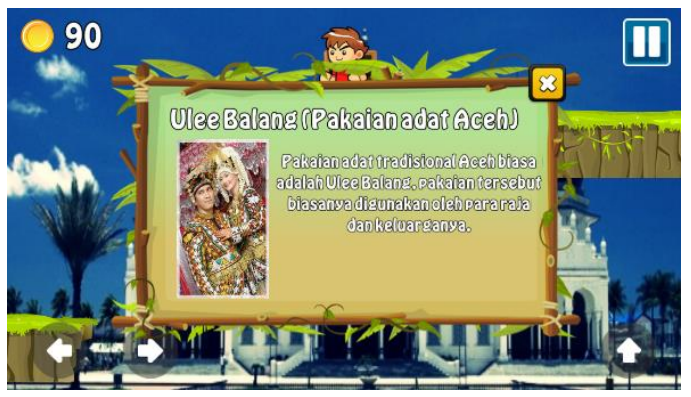

Gambar 14. Tampilan menu buka peti

e. Pengujian (testing)

Pada tahap pengujian dilakukan dengan menggunakan dua metode yaitu alpha beta. Pada pengujian alpha, menggunakan aspek functionality dengan metode blackbox. Hasil pengujian didapatkan $100 \%$ valid. Hal tersebut menandakan fungsi dalam game berjalan dengan baik. Pada tabel 2, adalah hasil pengujian alpha.

Tabel 2. Hasil Pengujian Blackbox

\begin{tabular}{cccc}
\hline No & $\begin{array}{c}\text { Komponen yang } \\
\text { diuji }\end{array}$ & $\begin{array}{c}\text { Skenario butir } \\
\text { uji }\end{array}$ & Hasil \\
\hline 1 & Tampilan Awal & $\begin{array}{l}\text { Memilih } \\
\text { Tombol }\end{array}$ & Berhasil \\
\hline
\end{tabular}

\begin{tabular}{|c|c|c|c|}
\hline 2 & $\begin{array}{ll}\text { Pilih } & \text { Tombol } \\
\text { Main } & \end{array}$ & $\begin{array}{l}\text { Ke halaman } \\
\text { Main }\end{array}$ & Berhasil \\
\hline 3 & $\begin{array}{l}\text { Pilih tombol } \\
\text { Provinsi }\end{array}$ & $\begin{array}{l}\text { ke halaman } \\
\text { provinsi }\end{array}$ & Berhasil \\
\hline 4 & $\begin{array}{ll}\text { Pilih } & \text { tombol } \\
\text { tentang } & \\
\end{array}$ & $\begin{array}{l}\text { ke halaman } \\
\text { tentang }\end{array}$ & Berhasil \\
\hline 5 & $\begin{array}{ll}\begin{array}{l}\text { Pilih } \\
\text { credit }\end{array} & \text { tombol } \\
\end{array}$ & $\begin{array}{l}\text { ke halaman } \\
\text { crdit }\end{array}$ & Berhasil \\
\hline 6 & $\begin{array}{l}\text { Pilih } \\
\text { suara }\end{array}$ & $\begin{array}{l}\text { Mematikan } \\
\text { dan } \\
\text { menghidupkan } \\
\text { suara }\end{array}$ & Berhasil \\
\hline 7 & $\begin{array}{l}\text { Pilih Tombol } \\
\text { kembali }\end{array}$ & $\begin{array}{l}\text { Kembali } \\
\text { halaman } \\
\text { utama }\end{array}$ & Berhasil \\
\hline 8 & $\begin{array}{l}\text { Pilih } \\
\text { ulang }\end{array}$ & $\begin{array}{l}\text { Mengulang } \\
\text { kembali ke } \\
\text { awal }\end{array}$ & Berhasil \\
\hline 9 & $\begin{array}{l}\text { Pilih } \\
\text { Pause }\end{array}$ & $\begin{array}{l}\text { Permainan } \\
\text { berhenti, dan } \\
\text { muncul } \\
\text { tampilan } \\
\text { Paused }\end{array}$ & Berhasil \\
\hline 10 & $\begin{array}{l}\text { Pilih Tombol } \\
\text { Panah Maju }\end{array}$ & Bergerak Maju & Berhasil \\
\hline 11 & $\begin{array}{l}\text { Pilih Tombol } \\
\text { Panah Mundur }\end{array}$ & $\begin{array}{l}\text { Bergerak } \\
\text { Mundur }\end{array}$ & Berhasil \\
\hline 12 & $\begin{array}{l}\text { Pilih Tombol } \\
\text { Lompat }\end{array}$ & $\begin{array}{l}\text { Karakter akan } \\
\text { lompat }\end{array}$ & Berhasil \\
\hline 13 & $\begin{array}{l}\text { Pilih Tombol } \\
\text { Resume atau exit }\end{array}$ & $\begin{array}{l}\text { Akan } \\
\text { melanjutkan } \\
\text { atau keluar } \\
\text { game }\end{array}$ & Berhasil \\
\hline
\end{tabular}

Pada pengujian beta, menggunakan usability yang ditujukan ke pengguna game. Dari hasil pengujian didapatkan hasil $80 \%$. Hal tersebut dapat disimpulkan aplikasi dapat diterima pengguna dengan baik dan cukup menarik. Hasil Pengujian Beta dapat dilihat pada tabel 3 berikut.

Tabel 3. Hasil pengujian Beta

\begin{tabular}{|c|c|c|c|c|c|c|}
\hline \multirow{2}{*}{ No } & \multirow{2}{*}{ Pernyataan } & \multicolumn{5}{|c|}{ Jawaban } \\
\hline & & SS & $\mathbf{S}$ & & TS & $\begin{array}{l}\text { STS } \\
\end{array}$ \\
\hline 1 & $\begin{array}{l}\text { apakah } \\
\text { Tampilan Game } \\
\text { Menarik }\end{array}$ & $35 \%$ & $55 \%$ & $20 \%$ & & \\
\hline 2 & $\begin{array}{l}\text { Apakah Game } \\
\text { mudah } \\
\text { digunakan }\end{array}$ & $63 \%$ & $15 \%$ & $12 \%$ & $10 \%$ & \\
\hline 3 & $\begin{array}{l}\text { Apakah game } \\
\text { ini sulit dari } \\
\text { tingkat } \\
\text { kesulitannya }\end{array}$ & $60 \%$ & & $40 \%$ & & \\
\hline 4 & $\begin{array}{l}\text { Apakah game } \\
\text { ini dapat } \\
\text { memberikan } \\
\text { wawasan epada } \\
\text { pengguna } \\
\text { tentang pakaian } \\
\text { adat Sumatera }\end{array}$ & $13 \%$ & $47 \%$ & $28 \%$ & $12 \%$ & \\
\hline
\end{tabular}


Pengujan Beta selanjutnya yaitu, Pengujian Sistem Operasi yang dilakukan pada beberapa macam sistem operasi dan perangkat. Hasil pengujian dapat dilihat pada tabel 4 berikut.

Tabel 4. Hasil Pengujian dengan berbagai perangkat dan sistem operasi.

\begin{tabular}{|c|c|c|c|}
\hline $\begin{array}{l}\text { Sistem } \\
\text { Operasi }\end{array}$ & Perangkat & Spesifikasi & $\begin{array}{l}\text { Hasil } \\
\text { Pengujian }\end{array}$ \\
\hline Kitkat & $\begin{array}{l}\text { Xioami } \\
\text { Redmi 1S }\end{array}$ & $\begin{array}{l}\text { Resolusi } \\
\text { Layar } \\
720 \times 1280 \\
\text { pixel, } \\
\text { RAM } 1 \mathrm{~Gb} \text {, } \\
\text { Processor } \\
1,6 \mathrm{Ghz}\end{array}$ & $\begin{array}{l}\text { Pada saat } \\
\text { membuka } \\
\text { game } \\
\text { sedikit } \\
\text { loading, } \\
\text { berjalan } \\
\text { baik pada } \\
\text { semua fitur }\end{array}$ \\
\hline Lolipop & $\begin{array}{l}\text { Lenovo } \\
\text { A6010 }\end{array}$ & $\begin{array}{l}\text { Resolusi } \\
\text { Layar } \\
720 \times 1280 \\
\text { pixel, } \\
\text { RAM } 1 \mathrm{~Gb} \text {, } \\
\text { Processor } \\
\text { 1,2 Ghz }\end{array}$ & $\begin{array}{l}\text { Pada saat } \\
\text { membuka } \\
\text { game } \\
\text { cukup } \\
\text { lancar, } \\
\text { berjalan } \\
\text { baik pada } \\
\text { semua fitur }\end{array}$ \\
\hline Marshmello & $\begin{array}{l}\text { Xiaomi } \\
\text { Redmi 3S }\end{array}$ & $\begin{array}{l}\text { Resolusi } \\
\text { Layar } \\
720 \times 1280 \\
\text { pixel, } \\
\text { RAM } 3 \mathrm{~Gb} \text {, } \\
\text { Processor } \\
\text { 1,4 Ghz }\end{array}$ & $\begin{array}{l}\text { Pada saat } \\
\text { membuka } \\
\text { game } \\
\text { lancar, } \\
\text { berjalan } \\
\text { baik pada } \\
\text { semua fitur }\end{array}$ \\
\hline Nougat & $\begin{array}{l}\text { Xiaomi M } \\
\text { A1 }\end{array}$ & $\begin{array}{l}\text { Resolusi } \\
\text { Layar } \\
\text { 1080x1920 } \\
\text { pixel, } \\
\text { RAM } 4 \mathrm{~Gb} \text {, } \\
\text { Processor } \\
2,2 \mathrm{Ghz}\end{array}$ & $\begin{array}{l}\text { Pada saat } \\
\text { membuka } \\
\text { game } \\
\text { sangat } \\
\text { lancar, } \\
\text { berjalan } \\
\text { baik pada } \\
\text { semua fitur }\end{array}$ \\
\hline
\end{tabular}

Dari hasil pengujan dapat disimpulkan bahwa aplikasi Game Explore sumatra Island dapat berjalan dengan baik dan dapat digunakan.

\section{Kesimpulan}

Berdasarkan pembahasan yang telah diuraikan maka peneliti telah membangun sebuah aplikasi Game Explore Sumatera Island yang bertujuan untuk mengenalkan dan mencoba melestarikan budaya bangsa berupa pakaian adat sumatera. Dalam pembangunan aplikasi peneliti menggunakan metode luther yang terdiri dari enam tahap concept, design, assembly, material collecting, testing dan distribution. Pada tahap design, peneliti menggunakan flowchart dan storyboard. Pada tahap pembuatan game menggunakan Construct 2 dan beberapa beberapa Tools pendukung lainnya seperti Corel Draw X5, Photoshop CS6. Dari hasil pengujian dengan menggunakan dua metode yaitu alpha (black box) dan betha (kuisioner) pengujian menggunakan metode blackbox mendapatkan hasil total presentase $100 \%$ valid. Hasil pengujian menggunakan Metode betha (kuisioner) mendapatkan hasil memuaskan dengan total presentase $80 \%$.

\section{Daftar Pustaka}

[1] Adiwijaya, M., Imam, K., \& Yuli Christyono., 2015. Perancangan Game Edukasi Platform Belajar Matematika Berbasis Android Menggunakan Construct 2,UNDIP, Semarang.

[2] Binanto, I., 2010, Multimedia Digital Dasar Teori+Pengembangannya, Andi Offset, Yogyakarta

[3] Yunanto, A.T, Fiayanto, A.Y.A, dan Wahyu Hidayat., 2015. Penciptaan Buku Ilustrasi Pakaian Adat Bregada Hadiningrat Keraton Yogyakarta Sebagai Upaya Pengenalan Pakaian Tradisional Kepada Anak-anak, STIKOM. Surabaya.

[4] Pressman, R.S., 2002, Rekayasa Perangkat Lunak Pendekatan Praktisi (Buku satu), Yogyakarta : Andi.

[5] Rahadi, R.M., Kodrat, I.S. dan Ike, P.I., "Perancangan Game Math Advanture Sebagai Media Pembelajaran Matematika Berbasis Android". Teknologi dan Sistem Komputer, Volume 4, No. 1 Januari 2016.

[6] Sumatra, last edit 2 December 2020, https://en.wikipedia.org/wiki/Sumatra. Diakses [7 Desember 2020].

[7] S. Ahdan, T. Pambudi, A. Sucipto, and Y. A. Nurhuda, "Game untuk Menstimulasi Kecerdasan Majemuk pada Anak (Multiple Intelligence) Berbasis Android", SENTER, pp. 554-568, Mar. 2020.

[8] Zulkarnais, A., Prasetyawan. P., Sucipto. A.,"Game Edukasi Pengenalan Cerita Rakyat Lampung Pada Platform Android". Jurnal Informatika: Jurnal Pengembangan IT, 3(1), p. 96. 2018.

[9] Adrian Q.J., Apriyanti," Game Edukasi Pembelajaran Matematika Untuk Anak Sd Kelas 1 Dan 2 Berbasis Android”. Jurnal Informatika: Jurnal TEKNOINFO, Vol.13, No.1, p. 51-54, ISSN: 2615-224X. 2019.

[10] Palendera Y., Fernando Y., Rizkiono D.R.," Game Detektif Resimen Mahasiswa Batalyon 209 Teknokrat Gajah Lampung". Jurnal Informatika: Jurnal TEKNOINFO, Vol.13, No.1, 2, p. 46-50, ISSN: 2615-224X. 2019. 